Jurnal SEOI - Fakultas Teknik Universitas Sahid Jakarta

Vol 3 edisi 2 tahun 2021

\title{
BIOAKUMULASI LOGAM BERAT PADA AVICENNIA MARINA DITAMAN WISATA ALAM MANGROVE ANGKE KAPUK JAKARTA
}

\section{BIOACCUMULATED ON HEAVY METALS IN AVICENNIA MARINA IN ANGKE KAPUK MANGROVE NATURAL TOURISM PARK JAKARTA}

\author{
Mira Sepnawati Jaya ${ }^{1}$, Maya Dewi Dyah Maharani ${ }^{2}$, Laila Febrina ${ }^{3}$ \\ ${ }^{1}$ Teknik Lingkungan, Fakultas Teknik, Jurusan Universitas Sahid Jakarta, Jl. Prof. Dr. Soepomo, SH No.84 Tebet \\ Jakarta, Email : mirrasepnawati@gmail.com \\ ${ }^{2}$ Teknik Lingkungan, Fakultas Teknik, Jurusan Universitas Sahid Jakarta, Jl. Prof. Dr. Soepomo, SH No.84 Tebet \\ Jakarta, Email:maya@usahid.ac.id \\ ${ }^{3}$ Teknik Lingkungan, Fakultas Teknik, Jurusan Universitas Sahid Jakarta, Jl. Prof. Dr. Soepomo, SH No.84 Tebet \\ Jakarta, Email : Laila_Febrina@usahid.ac.id
}

\begin{abstract}
ABSTRAK
Logam berat merupakan salah satu penyebab kerusakan ekosistem perairan paling besar disebabkan oleh kegiatan industrialisasi. Logam berat yang masuk dalam perairan sungai sebelum akhirnya akan mengalir ke lautan akan bermuara ke muara sungai yang biasanya terdapat ekosistem mangrove. Mangrove Avicenniamarina merupakan mangrove yang dapat digunakan sebagai indikator biologis lingkungan yang tercemar logam berat terutama $\mathrm{Cu}, \mathrm{Pb}$, dan $\mathrm{Zn}$. Maka perlu dilakukan identifikasi jumlah kandungan logam berat $\mathrm{Cu}, \mathrm{Pb}$, dan $\mathrm{Zn}$ dalam akar mangrove Avicennia marina dan menganalisis nilai bio-concentration factor (BCF) mangrove Avicennia marina untuk mengetahui kemampuannya dalam mengakumulasi logam beratperairan. Metode penelitian yang digunakan dalam penelitian ini adalah metode pola random sampling dandianalisis dengan menggunakan ICP-OES. Penelitian ini menghasilkan kandungan logam berat $\mathrm{Cu}, \mathrm{Pb}$, dan $\mathrm{Zn}$ di Taman Wisata Alam Mangrove Angke Kapuk di perairan rata-rata adalah $0,021 \mathrm{mg} / \mathrm{L}, 0,003 \mathrm{mg} / \mathrm{L}$, dan 0,3804 mg/L. Sedangkan kandungan logam berat $\mathrm{Cu}, \mathrm{Pb}$, dan $\mathrm{Zn}$ pada sludge rata rata adalah $0,4659 \mathrm{mg} / \mathrm{Kg}, 0,2180 \mathrm{mg} / \mathrm{Kg}$, dan $2,3518 \mathrm{mg} / \mathrm{Kg}$. Kandungan logam berat $\mathrm{Cu}, \mathrm{Pb}$, dan $\mathrm{Zn}$ di akar rata-rata adalah8,7950 mg/Kg, 0,9592 $\mathrm{mg} / \mathrm{Kg}$, dan $14,7934 \mathrm{mg} / \mathrm{Kg}$. Kemampuan mangrove Avicennia marina dalam mengakumulasi logam $\mathrm{Cu}, \mathrm{Pb}$, dan $\mathrm{Zn}$ masing-masing adalah 19,15; 4,16; dan 6,31. Nilai BCF melebihi satu menyatakan bahwa mangrove Avicennia marina di Taman Wisata Alam Mangrove Angke Kapuk Jakarta dapat mengakumulasikan logam berat.
\end{abstract}

Kata Kunci: Avicennia marina, Akar, BCF, ICP-OES

\section{ABSTRACT}

Heavy metals are one of the biggest causes of damage to aquatic ecosystems, caused by industrialization activities. Heavy metals in river waters before ending into the oceans will disembogue into the river mouth, which usually has mangrove ecosystems. Avicennia marina mangrove can be used as a biological indicatorfor the environment contaminated with heavy metals, especially $\mathrm{Cu}, \mathrm{Pb}$, and $\mathrm{Zn}$. Therefore, identification of $\mathrm{Cu}, \mathrm{Pb}$, and $\mathrm{Zn}$ heavy metal content in Avicennia marina mangrove roots and analyzing the bio- concentration factor $(B C F)$ value of Avicennia marina mangrove need to figure out its ability to accumulatewater heavy metals. The research method used was a random sampling pattern method and analyzed usingICP-OES. The research resulted from heavy metal that consists $\mathrm{Cu}, \mathrm{Pb}$, and $\mathrm{Zn}$ in Taman Wisata Alam Mangrove Angke Kapuk average in waters was $0.021 \mathrm{mg} / \mathrm{L}, 0.003 \mathrm{mg} / \mathrm{L}$, and $0.3804 \mathrm{mg} \mathrm{L}$. Meanwhile, theheavy metal content of $\mathrm{Cu}, \mathrm{Pb}$, and $\mathrm{Zn}$ average in sludge was $0.4659 \mathrm{mg} / \mathrm{Kg}, 0.2180$ $\mathrm{mg} / \mathrm{Kg}$, and $2.3518 \mathrm{mg} / \mathrm{Kg}$. The heavy metals content of $\mathrm{Cu}, \mathrm{Pb}$, and $\mathrm{Zn}$ average in the roots was 8,7950 
Jurnal SEOI - Fakultas Teknik Universitas Sahid Jakarta

Vol 3 edisi 2 tahun 2021

$\mathrm{mg} / \mathrm{Kg}, 0,9592 \mathrm{mg} / \mathrm{Kg}$, and $14,7934 \mathrm{mg} / \mathrm{Kg}$. The ability of Avicennia marina mangroves to accumulate $\mathrm{Cu}, \mathrm{Pb}$ and $\mathrm{Zn}$ metals were 19.15; 4.16; and 6.31. BCF value of more than one indicates that Avicennia marina mangroves in the Taman Wisata Alam Mangrove Angke Kapuk can accumulate heavy metals. Keywords: Avicennia marina, roots, BCF, ICP-OES

\section{PENDAHULUAN}

Sumber pencemar logam berat berasaldari sampah, minyak, dan limbah. Logam berat adalah salah satu penyebab kerusakan ekosistem perairan paling besar yang merupakan hasil akhir yang disebabkan olehindustrialisasi. Logam berat merupakan limbah yang paling berbahaya karena menimbulkan efek racun bagi manusia. Logam berat yang masuk ke lingkungan perairan sungai akan terlarut dalam air dan akan terakumulasi dalam sluge dan dapatbertambah sejalan dengan berjalannyawaktu, tergantung pada kondisi lingkungan perairan tersebut (Wulan dkk., 2013 dalam Utami, dkk., 2018). Logam berat dapat berpindah dari lingkungan ke organisme, dan dari organisme satu ke organisme lain melalui rantai makanan. Biota laut yang mencari makan di dasar perairan (udang, kerang, kepiting) akan memiliki peluang yang sangat besar untuk terkontaminasi logam berat tersebut. Hal ini juga membahayakan bagi masyarakat yangbertempat tinggal di sekitarnya dan utamanya masyarakat yang mengkonsumsi hasil laut yang telah terkontaminasi logam berat (Utami, dkk., 2018). Maka sebelum masuknya logam berat ke badan perairanlalu lautan kadarnya seharusnya di bawah ambang batas yang telah ditetapkan.

Logam berat yang masuk dalam perairan sungai sebelum akhirnya akanmengalir ke lautan akan bermuara ke muarasungai yang biasanya terdapat ekosistem mangrove. Salah satu muara yang terdapat ekosistem mangrove adalah Muara Angke yang berdekatan dengan Taman Wisata Alam Mangrove (TWAM) Angke Kapukyang akan dibahas pada penelitian ini. Mangrove memiliki fungsi fisik dalam penetrasi pencemaran perairan berperan menanggulangi pencemaran logam berat. Hutan mangrove merupakan agen bioremidiasi alami karena secara alamimangrove dapat menyerap kandunganlogam berat di alam seperti $\mathrm{Fe}, \mathrm{Mn}, \mathrm{Cr}, \mathrm{Cu}, \mathrm{Co}, \mathrm{Ni}, \mathrm{Pb}, \mathrm{Zn}$ dan $\mathrm{Cd}$ dan fungsi ini disebutsebagai biosorbsi (Hastuti, dkk., 2013 dalamUtami, dkk., 2018). Mangrove juga memilikikemampuan yang disebut biofilter yaitu kemampuan untuk menyaring, mengikat dan (BCF) dalam akar mangrove Avicennia marina dengan di perairan sehingga dapat dijadikan indikator bahwa tanaman mangrove di Taman Wisata Alam Mangrove memerangkap polusi di alam bebas berupa kelebian sludge, sampah, dan limbah buangan rumah tangga lainnya. Fungsi ini berperan dalam meningkatkan kualitas air (Gunarto, 2004 dalam Utami, dkk., 2018).

Penelitian ini dilakukan di Perairan TWAM Angke Kapuk Jakarta karena kawasan ini memiliki ekosistem mangrove yang cukup luas dan perkembangan bangunan tepi pantai (Water Front city) yang sangat pesat serta sampai saat ini belumbanyak penelitian terkait kemampuan mangrove dalam mengakumulasi logam berat. Penelitian Hamzah dan Setiawan (2010) menyatakan bahwa konsentrasilogam di Muara Angke pada sludge cukup tinggi, yaitu konsentrasi logam berat $\mathrm{Cu}$ totalbekisar antara 28,41-51,36 ppm, konsentrasilogam berat $\mathrm{Pb}$ total bekisar antara 56,58- 69,30 ppm, konsentrasi logam berat $\mathrm{Cu}$ totalberkisar antara 18,64-29,57 ppm. Banyaknya aktivitas industri seperti industrijasa pemotongan lembaran logam, produksi baut, produksi alat-alat listrik, industri kabel,produksi plastik, dan distributor bahan kimiadi sekitar lokasi juga menjadi dugaan adanyalogam berat di sekitar kawasan tersebut. Logam berat yang akan diteliti adalah logamberat tembaga $(\mathrm{Cu})$, timbal $(\mathrm{Pb})$ dan seng $(\mathrm{Zn})$. Menurut Mukhtasar (2007) dalam Fadhilla dkk. (2018) Avicennia marina dapat digunakan sebagai indikator biologis lingkungan yang tercemar logam berat terutama $\mathrm{Cu}, \mathrm{Pb}$, dan $\mathrm{Zn}$ melalui pemantauan berkala.

Tujuan dari dilakukannya penelitianbioakumulasi logam berat pada Avicenniamarina di 
Jurnal SEOI - Fakultas Teknik Universitas Sahid Jakarta

Vol 3 edisi 2 tahun 2021

Taman Wisata Alam MangroveAngke Kapuk Jakarta adalah mengidentifikasi jumlah kandungan logamberat tembaga $(\mathrm{Cu})$, timbal $(\mathrm{Pb})$ dan $\operatorname{seng}(\mathrm{Zn})$ dalam akar mangrove Avicennia marina di Taman Wisata Alam Mangrove Angke Kapuk Jakarta. Kemudianmenganalisis nilai bio-concentration factor Angke Kapuk Jakarta dapat menyeraplogam-logam berat di perairan.

\section{METODE PENELITIAN}

\subsection{Jenis Penelitian}

Penelitian ini, penulis menggunakanjenis penelitian deskriptif menggunakanteknik analisis kuantitatif dengan menggunakan data primer yang diperolehdari pengambilan sampel di Taman Wisata Alam Mangrove Angke Kapuk Jakarta.

\subsection{Waktu Dan Tempat Penelitian}

Penelitian ini dilakukan pada bulan Oktober 2019 - April 2020. Pengambilan sampel dilakukan pada Sabtu, 21 Maret 2020di Taman Wisata Alam Mangrove Angke Kapuk Jakarta. Pengolahan sampel dan analisis $\mathrm{Cu}, \mathrm{Pb}$, dan $\mathrm{Zn}$ dilakukan diLaboratorium Lingkungan Hidup PT Karsa Buana Lestari, Jalan Bintaro Permai Raya No. 25, RT 06 / RW 01, Bintaro, KecamatanPesanggrahan, Kota Jakarta Selatan, DaerahKhusus Ibukota. Pengambilang sampel dilakukan pada 5 titik yang terlihat pada Gambar 1. disatu kawasan dengan titik koordinat sebagai berikut : Titik 1 :

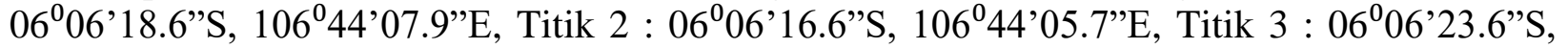

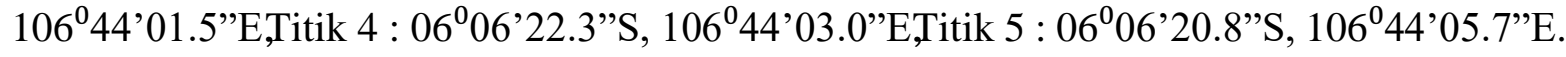

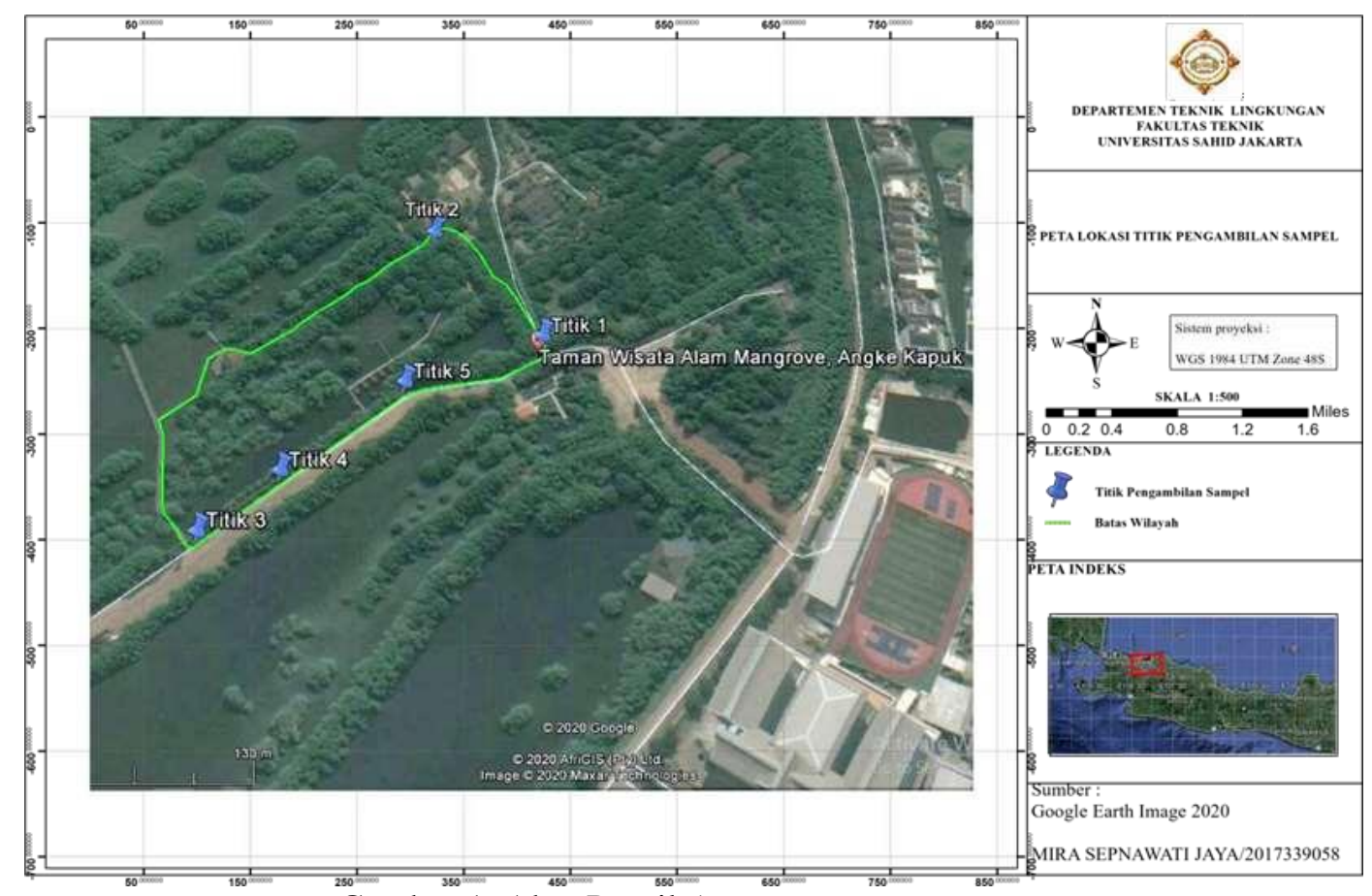

Gambar 1. Akar Pensil Avicennia Marina

Sumber : Google Earth Image 2020

\subsection{Tahap Penelitian}

Metode penelitian yang digunakan dalam penelitian ini adalah metode pola random sampling di Perairan Taman WisataAlam Angke Kapuk Jakarta. Sampel yang diambil adalah air, sludge, dan pohon mangrove Avicennia marina. Pohon Avicennia marina tumbuhan yang tingginyalebih dari $1,5 \mathrm{~m}$ dan berdiameter lebih dari $10 \mathrm{~cm}$ yang disampling sebanyak 5 titik sampling. Penelitian ini dilakukan dengan beberapa tahapan yang dijelaskan secara singkat 
Jurnal SEOI - Fakultas Teknik Universitas Sahid Jakarta

Vol 3 edisi 2 tahun 2021

dalam diagram alur kerangka penelitian pada Gambar 2.

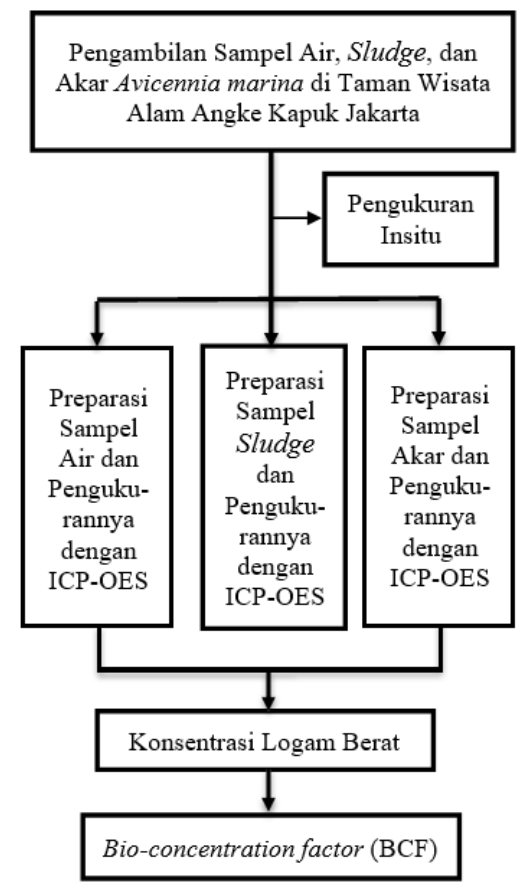

Gambar 2. Kerangka Penelitian

\subsubsection{Pengambilan Sampel Air, Sludge, dan Akar Avicennia marina}

Pengambilan sampel air diambil pada kedalaman $\pm 30 \mathrm{~cm}$ dari permukaan sebanyak 1000 $\mathrm{mL}$. Sampel yang di ambil dimasukkan ke dalam botol polietilen. Sampel air diawetkan dengan caramenambahkan $\mathrm{HNO}_{3}$ pekat hingga $\mathrm{pH}$ sampel bernilai <2. Kemudian sampel di masukkan ke dalam cool box, untuk selanjutnya dianalisa di laboratorium (Fadhilla dkk., 2018).

Sludge daerah muara sungai terjadi sebagai akibat adanya bawaan sungai berupalumpur tersuspensi (dalam bentuk suspensi)dalam jumlah besar, gerakkan gelombanglaut, dan air laut pasang yang menghadang di depan muara sungai dan arus laut yang datang dari kiri dan kanan mulut sungai.Proses pembentukkan sludge di daerahmuara sungai banyak dipengaruhi oleh faktor dan yang paling dominan berpengaruh sebagai berikut: : gelombang laut, debit sungai, dan pasang surut (Pane, 2008 dalam Chodiyah dan Palampita, 2019). Sehingga sampel sludge yang diambil dan yang akan dianalisa adalah sludge suspensi berbentuk lumpur dan lempung. Sampel sludge diambildengan menggunakan alat Bucket Auger danThin Wall-Tube Sampler berdasarkan SNI 8520:2018 (Sucita dkk., 2019). Alat Bucket Auger dan Thin Wall-Tube Sampler ini cukup sederhana dan mudah dibawa. Alat inidiperuntukkan untuk sampling di area berserat, berakar, dan berawa. Alat ini juga dapat melubangin area dengan kedalaman pengambilan sampel tertentu sesuai kebutuhan. Pengambilan sampel sludge dilakukan dengan memasukkan Bucket Auger dan Thin Wall-Tube Sampler sampai kedalaman $\pm 30 \mathrm{~cm}$. Sampel sludge dimasukkan kedalam plastik, kemudian dimasukkan kedalam cool box, untuk selanjutnya dianalisa di laboratorium.

Bagian akar A. marina yang diambil adalah berupa akar pensil (bagian yang terendam di dalam sludge karena kemungkinan akumulasi logam berat pada bagian ini lebih banyak daripada bagian lainnya) yang dapat dilihat pada Gambar 3. Akar A. marina yang diambil berdiameter $\pm 1 \mathrm{~cm}$ dan panjang $20 \mathrm{~cm}-30 \mathrm{~cm}$. Pengambilan sampel dilakukan secara langsung dengan menggunakan alat potong, masing-masing sampel diambil kurang lebih 100 gram dan dimasukkan kedalam plastik, setelah itu sampel dimasukkan ke dalam cool box, untuk 
Jurnal SEOI - Fakultas Teknik Universitas Sahid Jakarta

Vol 3 edisi 2 tahun 2021

selanjutnya dianalisa di laboratorium (Fadhilla dkk., 2018).

\subsubsection{Pengukuran Insitu}

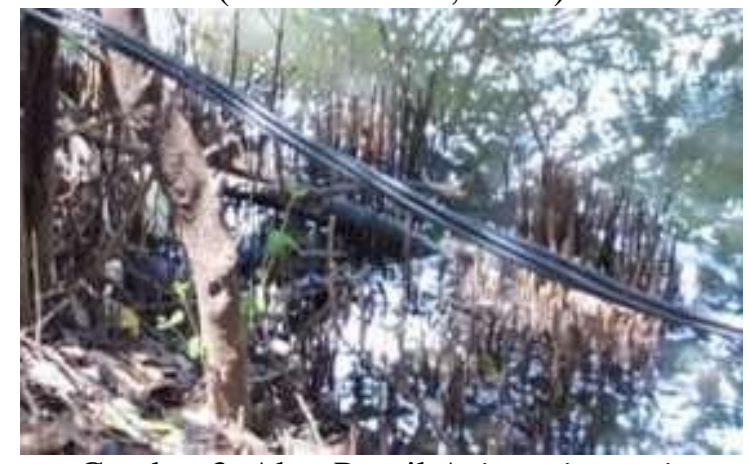

Gambar 3. Akar Pensil Avicennia marina

Sumber : Dokumentasi Penulis, 2020

Pengukuran insitu dilakukan terhadap sampel air, parameter yang dilakukan pengujian adalah parameter $\mathrm{pH}$, suhu, kandungan oksigen terlarut (DO) dan salinitas. $\mathrm{pH}$ air diukur dengan menggunakan $\mathrm{pH}$ meter. Suhu diukur dengan menggunakan termometer digital. Kandungan oksigen terlarut diukur dengan DO meter. Salinitas diukur dengan alat refraktometer.

\subsubsection{Preparasi Sampel Air dan Pengukurannyadengan ICP-OES}

Sampel air untuk pengujian tembaga $(\mathrm{Cu})$, timbal $(\mathrm{Pb})$, dan Seng $(\mathrm{Zn})$ total dipreparasi dengan acuan Application Note CETAC Method for SPR Beads dan diukur dengan acuan APHA 3120B. Sampel dihomogenkan lalu dipipet $10 \mathrm{~mL}$ dan dimasukkan ke dalam tabung sentrifuge. Sampel kemudian disentrifuge selama 10menit, setelah itu ditambahkan SPR-IDA sebanyak 50

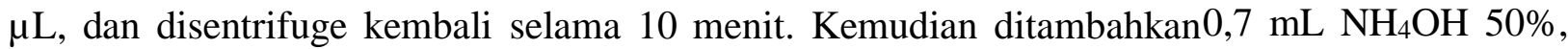
diaduk lalu pastikan pH nya 8-8,5, diatur dengan penambahan $\mathrm{NH}_{4} \mathrm{OH} 50 \%$ atau $\mathrm{HNO}_{3} 20 \%$. Setelah itu disentrifuge kembali selama 1 jam dengan kecepatan 5000 rpm. Sampel yang disentrifuge akan menghasilkan cairanjernih dan endapan, cairan jernih dibuang dan endapan yang mengandung logam dilarutkan kembali dengan $1 \mathrm{~mL} \mathrm{HNO}_{3} 20 \%$ lalu ditambahkan air suling dan dihomogenkan. Sampel siap diukur serapannya dengan alat Inductively CoupledPlasma-Optical Emission Spectrometry (ICP-OES).

\subsubsection{Preparasi Sampel Sludge dan Pengukurannya dengan ICP-OES}

Sampel sludge untuk pengujian tembaga $(\mathrm{Cu})$, timbal $(\mathrm{Pb})$, dan Seng $(\mathrm{Zn})$ total dipreparasi dan diukur dengan acuan USEPA 1311 dan APHA 3120B. Sampel dipreparasi untuk diukur pHnya, $\mathrm{pH}$ yang dihasilkan digunakan untuk menentukan penguaan larutan ektraksi. Setelah itu sampel sludge ditimbang dan dimasukkan kedalam vessel. Sampel yang telah ditimbang ditambahkan larutan ekstrak dan diektraksi dengan alat ekstraktor selama 18 jam, kecepatan berputar $30 \mathrm{rpm} \pm 2$. Setelahdiekstrak larutan dikeluarkan dan disaring, cairan hasil saringan ditampung. Sampel siap diukur serapannya dengan alat Inductively Coupled Plasma-Optical Emission Spectrometry (ICP-OES).

\subsubsection{Preparasi Sampel Akar dan Pengukurannya dengan ICP-OES}

Sampel akar untuk pengujian tembaga $(\mathrm{Cu})$, timbal $(\mathrm{Pb})$, dan Seng $(\mathrm{Zn})$ total dipreparasi dan diukur dengan acuan SNI 6989.6:2009 untuk logam Cu, SNI 6989.7:2009 untuk timbal logam Zn, SNI 6989.8:2009 untuk logam Pb, dan APHA 3120B untuk pengukurannya. Preparasi sampel akar A. marina dilakukan denganmencacah akar sehingga berukuran kecil.Sampel akar yang telah dicacah diletakkan di cawan penguap dan dipanaskan dalamoven pada suhu $105^{\circ} \mathrm{C}$ selama 12 jam. Sampel akar yang kering dihaluskan denganblender, lalu ditimbang sebanyak 1 gram kedalam gelas piala kemudian dicatat beratnya (W). Sampel yang telah ditimbang ditambahkan secara 
Jurnal SEOI - Fakultas Teknik Universitas Sahid Jakarta

Vol 3 edisi 2 tahun 2021

berurutan $5 \mathrm{~mL}-10 \mathrm{mLHNO}_{3}$ pekat lalu, didekstruksi sampai sisa volumenya $15 \mathrm{~mL}$ - $20 \mathrm{~mL}$. Jika destruksi belum sempurna (tidak jernih), maka tambahkan lagi $5 \mathrm{~mL} \mathrm{HNO}_{3}$ pekat. Lakukanproses ini secara berulang sampai semua logam larut, yang terlihat dari warna endapan dalam sampel menjadi agak putih atau sampel menjadi jernih. Kaca arloji dibilas dengan air dan masukkan air bilasannya ke dalam gelas piala. Sampel dipindahkan ke dalam labu ukur $50 \mathrm{~mL}$ (disaring bila perlu) dan ditambahkan airsuling sampai tepat tanda tera dan dihomogenkan. Sampel siap diukur serapannya dengan alat Inductively CoupledPlasma-Optical Emission Spectrometry (ICP-OES).

\subsection{Proses Analisis Data}

Analisis data dilakukan dengan analisis deskriftif kuantitatif dengan menghitung akumulasi logam pada mangrove. Mengetahui terjadi akumulasi logam pada mangrove dilakukan dengan cara menghitung konsentrasi logam pada air,sludge, dan akar. Perbandingan antara konsentrasi logam di akar dengan konsentrasi di lingkungan dikenal denganbio-concentration factor (BCF). BCF pada akar dihitung untuk mengetahui seberapabesar konsentrasi logam pada akar yang berasal dari lingkungan (MacFarlane dkk., 2007 dalam Awaliyah dkk., 2018).

\subsubsection{Konsentrasi Logam Berat}

Rumus konsentrasi logam berat padasampel air mangrove A. marina, yaitu : Konsentrasi logam $(\mathrm{mg} / \mathrm{L})=$ Konsentrasilogam ICP Sedangkan rumus konsentrasi logamberat pada sampel sludge dan akar mangrove A. marina, yaitu :

Konsentrasi logam $(\mathrm{mg} / \mathrm{Kg}) \equiv$ Konsentrasi logam ICP $(\mathrm{mg} / \mathrm{L}) \times$ volume labu $(\mathrm{L})$

\subsubsection{Bio-concentration factor (BCF)}

Bobot sampel $(\mathrm{Kg})$

Bio-concentration factor (BCF) adalahkonsentrasi suatu senyawa didalam suatu organisme percobaan dibagi dengan konsentrasi senyawa tersebut dalam medium sludge satuannya (mg/L). Menurut MacFarlane dkk. (2003) dalam Awaliyahdkk. (2018) Bio-concentration factor (BCF) dapat dihitung dengan menggunakan rumus:Bio-concentration factor $(\mathrm{BCF})=$

Konsentrasi Logam Berat pada Akar $\left(\frac{\mathrm{mg}}{\mathrm{Kg}}\right)$

Konsentrasi Logam Berat pada sludge $\left(\frac{\mathrm{mg}}{\mathrm{Kg}}\right)$

Baker (1981) dalam Awaliyah dkk. (2018) menyatakan bahwa nilai BCF untuk mengetahui kemampuan mangrove dalam menyerap polutan dari lingkungan ke bagianakar. Janssen dkk. (1997) dalam Fadhilla et (2018) menyatakan bahwa apabila nilai BCF > 1 dari konsentrasi yang ada dikolom sludge berarti organisme tersebut memiliki kemampuan mengakumulasi logam dalam tubuhnya (hiperakumulator), sebaliknya $\mathrm{BCF} \leq 1$, berarti organisme kurang memilikikemampuan mengakumulasi logam dalam tubuhnya. Pada perhitungan penelitian ini yang dijadikan pembanding adalah sludge karena akar A. marina berinteraksi langsungdengan sludge.

Konsentrasi logam berat $\mathrm{Cu}, \mathrm{Pb}$, dan $\mathrm{Zn}$ pada air dibandingkan dengan KEPMENLH No. 51 Tahun 2004 Lampiran III tentangbaku mutu air laut untuk biota. Konsentrasi $\mathrm{Cu}, \mathrm{Pb}$, dan $\mathrm{Zn}$ pada sludge mengacu pada standar mutu sludge dalam Australian and New Zealand Environment and Conservation Council (ANZECC, 2000).

\section{Hasil Penelitian dan Pembahasan}

\subsection{Kondisi Fisik Kimiawi Perairan}

Kondisi fisik kimiawi perairan dilihat dari hasil pengukuran insitu yaitu parameterderajat keasaman $(\mathrm{pH})$, suhu, kandungan oksigen terlarut (DO), dan salinitas. Derajatkeasaman $(\mathrm{pH})$, suhu, kandungan oksigenterlarut (DO), dan salinitas memilikikerterkaitan satu dengan lainnya yang mengambarkan konsentrasi rendah tingginya logam dalam perairan.

Kondisi masing-masing titik samplinghampir sama pada awal sampling udaranya sejuk 
karena banyak pohon-pohon mangrove yang cukup rapat kemudian seiring berjalannya waktu menjadi agak cerah dan ada sinar-sinar matahari pagi karena waktu pengambilan sampel pagi hari yaitu pukul 07.43 WIB sampai 10.03 WIB Kondisi perairannya tenang, pada titik 1, titik 4, dan titik 5, berbatasan dengan jalan. Titik 2 percabangan air muara ke muara, dantitik 3 bersebrangan dengan aliran air dari muara menuju laut tetapi jaraknya cukupjauh.

\subsubsection{Derajat Keasaman (pH)}

Derajat keasaman atau yang lebih dikenal dengan $\mathrm{pH}$ di perairan Taman Wisata Alam Mangrove Angke Kapuk berkisar antara 6,83-6,98. Nilai pH terendahterdapat pada titik 5 dengan nilai $\mathrm{pH}$ sebesar6,83. Sementara nilai $\mathrm{pH}$ tertinggi terdapat pada titik 2 dengan nilai $\mathrm{pH} 6,98$ yang dapatdilihat pada Gambar 4.

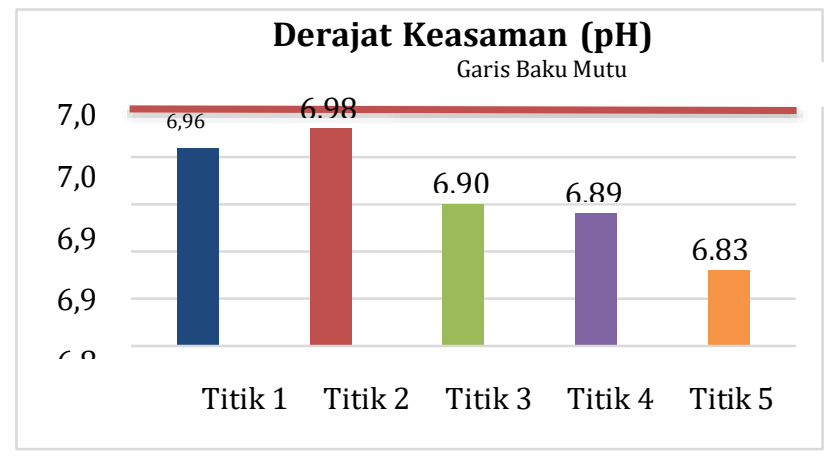

Gambar 4.Nilai Derajat Keasaman ( $\mathrm{pH})$ pada perairan Taman Wisata Alam Mangrove Sumber : Dokumentasi Penulis, 2020

Data yang didapat $\mathrm{pH}$ terendah terdapat pada titik 5 . Rendahnya $\mathrm{pH}$ pada titik 5 mengindikasikan tingginya konsentrasi logam berat $\mathrm{Cu}, \mathrm{Pb}$, dan $\mathrm{Zn}$ padaair di titik 5 . Menurut Palar (2004) dalam Supriyantini dkk. (2017), kenaikan pH akanmenurunkan kelarutan logam berat dalam airkarena kenaikan $\mathrm{pH}$ mengubah kestabilandari bentuk karbonat menjadi hidroksida yang membentuk ikatan dengan partikel pada badan air sehingga akan mengendap dalam sludge. Dikatakan bahwa nilai pHyang tinggi (basa), menyebabkan toksisitas logam berat berkurang, karena ion logammembentuk senyawa kompleks dengan senyawa lain yang ada di perairan sehingga akan mengendap di dasar perairan bersama sludge. Sebaliknya, $\mathrm{pH}$ rendah (asam) akan menyebabkan logam berat larut dalam air sehingga toksisitas tinggi.

Derajat keasaman di perairan TWAM Angke Kapuk berkisar antara 6,83-6,98 masih dibawah dari baku mutu Keputusan Menteri Lingkungan Hidup No. 51 Tahun 2004 Lampiran III yang menyatakan nilai $\mathrm{pH}$ perairan untuk biota laut 7-8,5. $\mathrm{pH}$ yangdiperoleh memang tidak begitu jauh daribaku mutu, $\mathrm{pH}$ asam dapat disebabkan menurunnya oksigen terlarut di dalam air dan proses reaksi reduksi dan oksidasi yangterjadi pada sludge diduga bisa mengurangi kandungan $\mathrm{pH}$.

\subsubsection{Suhu}

Suhu di perairan TWAM berkisar antara $26,5^{\circ} \mathrm{C}-27,6^{\circ} \mathrm{C}$. Suhu terendah terdapat pada titik 2 dan suhu tertinggi padatitik 5 yang dapat dilihat pada Gambar 5. Perbedaan suhu ini bisa disebabkan waktu pengambilan sampel, perbedaan intensitascahaya tingkat kerapatan mangrove. Titik 2 memiliki suhu terendah yaitu $26,5^{\circ} \mathrm{C}$ karena intensitas cahaya yang masuk sedikit disebabkan matahari belum bersinar maksimal dan pada titik ini dikelilingi oleh vegetasi mangrove. Sedangkan suhutertinggi pada titik 5 disebabkan intensitas cahaya yang masuk cukup karena langsung mendapat cahaya matahari di sebelah timur.Titik 5 mendapat cahaya matahari tanpa adahalangan dari vegetasi mangrove karena disebelah timurnya berbatasan dengan jalan. 
Jurnal SEOI - Fakultas Teknik Universitas Sahid Jakarta

Vol 3 edisi 2 tahun 2021

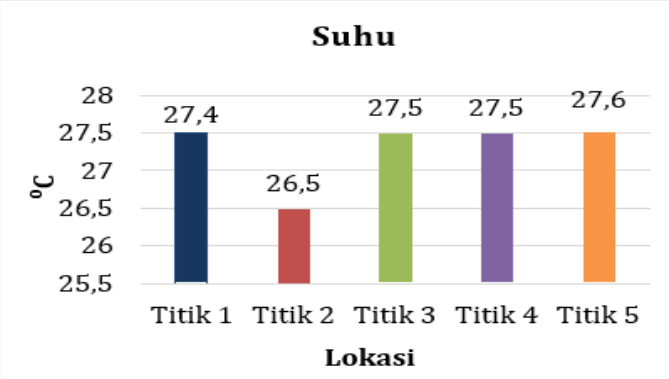

Gambar 5. Suhu pada perairan TamanWisata Alam Mangrove Sumber : Dokumentasi Penulis, 2020

Suhu diukur karena memiliki pengaruhterhadap kadar logam dalam perairan. Menurut Haiyan Li dkk. (2013) dalam Supriyantini dkk. (2017), suhumempengaruhi proses kelarutan logam berat yang masuk ke perairan, semakin tinggi suhuperairan maka kelarutan logam berat akan semakin tinggi sehingga toksisitas logam berat pun juga tinggi. Setelah mendapatkan hasil bahwa suhudi perairan TWAM berkisar antara $26,5^{\circ} \mathrm{C}-27,6^{\circ} \mathrm{C}$ maka dibandingkan dengan baku mutu. Baku mutu menurut Keputusan Menteri Lingkungan Hidup No. 51 Tahun 2004 Lampiran III menyatakan nilai suhu perairan untuk biota laut $28^{\circ} \mathrm{C}-32^{\circ} \mathrm{C}$, maka suhu di perairan TWAM Angke Kapuk masih kurang dari baku mutu. Suhu yang rendah ini disebabkan oleh waktu pengambilan sampel terlalu pagi sehingga matahari belum bersinar sempurna, dan suhuudara juga masih sangat sejuk karena ditanami vegetasi magrove yang cukuprapat.

3.1.3. Oksigen Terlarut (DO)

Oksigen terlarut atau dissolve oksigen(DO) di perairan TWAM berkisar antara0,95 mg/L$1,67 \mathrm{mg} / \mathrm{L}$. Nilai DO terendah terdapat pada titik 3 dengan nilai DO sebesar0,95 mg/L. Sementara nilai $\mathrm{pH}$ tertinggi terdapat pada titik 5 dengan nilai DO 1,67 mg/L yang dapat dilihat pada Gambar 6.

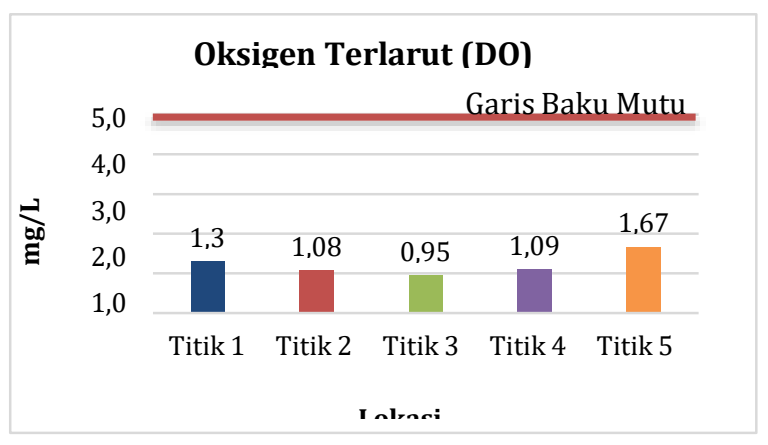

Gambar 6. Oksigen Terlarut (DO) pada perairan Taman Wisata Alam Mangrove Sumber : Dokumentasi Penulis, 2020

Menurut Effendi (2003) dalam Fadhilla dkk. (2018) hubungan antara oksigen terlarut dengan suhu adalah semakintinggi suhu maka oksigen terlarut akansemakin berkurang. Kenyataan di lapangan nilai oksigen terlarut tidak selalu berbandingterbalik dengan nilai suhu perairan. Oksigenterlarut pada titik 5 dan 1 cenderung lebih tinggi sedangkan suhunya juga tinggi. Oksigen terlarut pada titik 5 dan titik 1 cenderung lebih tinggi dikarenakan badan perairan di titik 1 dan 5 tidak mengalir sehingga DO yang dihasilkan lebih tinggi dibanding titik 2, titik 3 dan titik 4 .

Kadar oksigen juga mempengaruhi keberadaan logam berat di perairan. Baku mutu menurut Keputusan Menteri Lingkungan Hidup No. 51 Tahun 2004 Lampiran III menyatakan nilai DO lebih dari $5 \mathrm{mg} / \mathrm{L}$. Semua titik sampling memiliki nilaiDO $<5 \mathrm{mg} / \mathrm{L}$, yang menyatakan perairan 
Jurnal SEOI - Fakultas Teknik Universitas Sahid Jakarta

Vol 3 edisi 2 tahun 2021

yang kekurangan oksigen sehingga menyebabkan air mudah menguap, yang mempengaruhi konsentrasi logam berat yaitu akan berkurang. Hal ini sejalan dengan Napitu (2002) yang menyatakan bahwa daerah-daerah yang kekurangan oksigen dalam air, daya larut logam menjadi lebih rendah dan mudah menguap sehingga konsentrasi logam berat akan berkurang. Nilai DO yang kecil mengindikasikan adanya pencemaran bahan bahan organikyang cukup tinggi yang berasal dari limbah domestik masyarakat yang akhirnya bermuara di muara angke.

\subsubsection{Salinitas}

Salinitas diukur karena mempengaruhikadar logam di perairan. Salinitas di perairanTWAM berkisar antara 7\%o-10\%o. Salinitas terendah terdapat pada titik 2 dan 3 sementara pada suhu tertinggi pada titik 1, 4, dan 5 yang dapat dilihat pada Gambar 7.

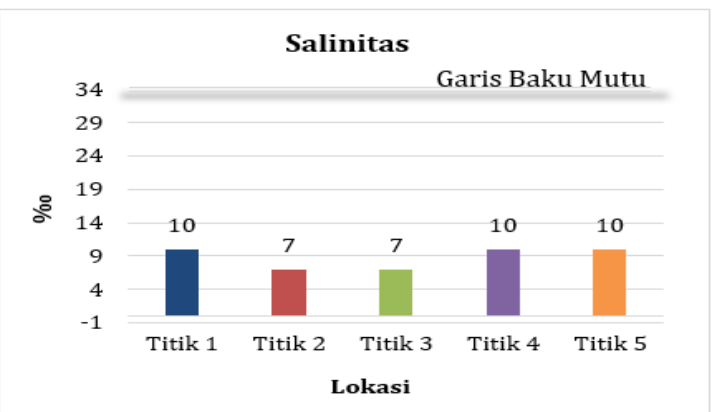

Gambar 7. Salinitas pada perairan TamanWisata Alam Mangrove Sumber : Dokumentasi Penulis, 2020

Mance (1987) dalam Supriyantini, E (2017) menyatakan, salinitas yang tinggi menyebabkan kandungan logam berat di perairan juga tinggi, begitu pula sebaliknya salinitas rendah menyebabkan logam berat di perairan rendah. Rendahnya salinitas di perairan menyebabkan daya toksisitas dan akumulasi $\mathrm{Pb}$ meningkat. Salinitas yang tinggi disebabkan oleh adanya penguapan yang tinggi. Baku mutu salinitas menurut Keputusan Menteri Lingkungan Hidup No. 51 Tahun 2004 Lampiran III menyatakan nilai salinitas s/d 34\%o, hasil pengukurantelah memasuki baku mutu, nilai salinitas tidak terlalu tinggi karena muara merupakanpercampuran antara air tawar dan air asin.

3.2 Konsentrasi Logam Berat Cu (Tembaga),Pb (Timbal), dan Zn (Seng) pada Air,Sludge, dan Akar.

Analisis konsentrasi logam dilakukan untuk menghitung akumulasi logam pada mangrove Avicennia marina.Sampel dinalisa dalam satu kawasan dandilakukan pada 5 titik. Kemudian dari 5 titikkita akan mendapat rata-rata konsentrasi logam $\mathrm{Cu}, \mathrm{Pb}$, dan $\mathrm{Zn}$ pada air, sludge, dan akar Avicennia marina. Konsentrasi logam berat tersebut dapat dilihat pada Tabel 1.

Tabel 1. Konsentrasi Logam Berat $\mathrm{Cu}, \mathrm{Pb}$, dan $\mathrm{Zn}$ pada Air, Sludge, dan Akar

\begin{tabular}{lccccccccc}
\hline \multirow{2}{*}{ Lokasi } & \multicolumn{3}{c}{ Konsentrasi Logam Cu } & \multicolumn{3}{c}{ Konsentrasi Logam Pb } & \multicolumn{2}{c}{ Konsentrasi Logam Zn } \\
\cline { 2 - 10 } & $\begin{array}{c}\text { Air } \\
(\mathbf{m g} / \mathbf{L})\end{array}$ & $\begin{array}{c}\text { Sludge } \\
(\mathbf{m g} / \mathbf{K g})\end{array}$ & $\begin{array}{c}\text { Akar } \\
(\mathbf{m g} / \mathbf{K g})\end{array}$ & $\begin{array}{c}\text { Air } \\
(\mathbf{m g} / \mathbf{L})\end{array}$ & $\begin{array}{c}\text { Sludge } \\
(\mathbf{m g} / \mathbf{K g})\end{array}$ & $\begin{array}{c}\text { Akar } \\
(\mathbf{m g} / \mathbf{K g})\end{array}$ & $\begin{array}{c}\text { Air } \\
(\mathbf{m g} / \mathbf{L})\end{array}$ & $\begin{array}{c}\text { Sludge } \\
(\mathbf{m g} / \mathbf{K g})\end{array}$ & $\begin{array}{c}\text { Akar } \\
(\mathbf{m g} / \mathbf{K g})\end{array}$ \\
\cline { 2 - 10 } Titik 1 & 0,027 & $\mathbf{0 , 5 4 9 9}$ & $\mathbf{1 0 , 6 9 6 5}$ & 0,002 & 0,2400 & 0,9991 & 0,3680 & 2,7398 & 16,8017 \\
Titik 2 & 0,020 & 0,6198 & 11,1150 & 0,002 & 0,3199 & 1,8482 & 0,3930 & 2,7800 & 16,9830 \\
Titik 3 & 0,015 & 0,4599 & 7,2471 & 0,002 & 0,2100 & 0,8996 & 0,3720 & 2,0797 & 13,4433 \\
Titik 4 & 0,011 & 0,3199 & 6,7698 & 0,003 & 0,1600 & 0,3498 & 0,3580 & 2,1196 & 13,5419 \\
Titik 5 & 0,030 & 0,3800 & 8,1484 & 0,008 & 0,1600 & 0,6993 & 0,4110 & 2,0398 & 13,1974 \\
\hline Rerata & $\mathbf{0 , 0 2 1}$ & $\mathbf{0 , 4 6 5 9}$ & $\mathbf{8 , 7 9 5 4}$ & $\mathbf{0 , 0 0 3}$ & $\mathbf{0 , 2 1 8 0}$ & $\mathbf{0 , 9 5 9 2}$ & $\mathbf{0 , 3 8 0 4}$ & $\mathbf{2 , 3 5 1 8}$ & $\mathbf{1 4 , 7 9 3 4}$ \\
\hline
\end{tabular}

Sumber : Data primer, 2020 
Jurnal SEOI - Fakultas Teknik Universitas Sahid Jakarta

Vol 3 edisi 2 tahun 2021

Berikut adalah contoh perhitungankonsentrasi logam berat pada sampel air Avicennia marina:

Konsentrasi logam $(\mathrm{mg} / \mathrm{L})=$ Konsentrasi logam ICP

Konsentrasi $\log a \mathrm{~m} \mathrm{Cu}(\mathrm{mg} / \mathrm{L})=0,027 \mathrm{mg} / \mathrm{L}$

Berikut adalah contoh perhitungan konsentrasi logam berat pada sludge air

Avicennia marina :

Konsentrasi logam $\mathrm{Cu}(\mathrm{mg} / \mathrm{Kg})$ Ulangan 1

$=\frac{\text { Konsentrasi logam ICP }(\mathrm{mg} / \mathrm{L}) \times \text { volume labu }(\mathrm{L})}{\text { Bobot sampel }(\mathrm{Kg})}$

$=\frac{0,022\left(\frac{\cdots}{\mathrm{L}} \times 0,05 \mathrm{~L}\right.}{25,0035 \mathrm{~g} \times 10^{-3} \mathrm{~g} / \mathrm{Kg}}=0,4399 \mathrm{mg} / \mathrm{Kg}$

Konsentrasi logam $\mathrm{Cu}(\mathrm{mg} / \mathrm{Kg})$ Ulangan 2

$=\frac{0,033\left(\frac{\mathrm{mg}}{\mathrm{x}} \times 0,05 \mathrm{~L}\right.}{25,0016 \mathrm{~g} \times 10^{-3} \mathrm{~g} / \mathrm{Kg}}=0,6600 \mathrm{mg} / \mathrm{Kg}$

Konsentrasi $\mathrm{Cu}(\mathrm{mg} / \mathrm{Kg})$

Konsentrasi Cu (Ulangan1) + Konsentrasi Cu (Ulangan2)

$=\frac{(0,4399+0,6600) \mathrm{mg} / \mathrm{Kg}^{2}}{2}=0.5499 \mathrm{mg} / \mathrm{Kg}$

Berikut adalah contoh perhitungan konsentrasi logam berat pada akar air Avicennia marina :

Konsentrasi logam $\mathrm{Cu}(\mathrm{mg} / \mathrm{Kg})$ Ulangan 1

$=\frac{\text { Konsentrasi logam ICP }(\mathrm{mg} / \mathrm{L}) \times \text { volume labu }(\mathrm{L})}{}$

$=\frac{0,246\left(\frac{\mathrm{mg}}{\mathrm{L}}\right) \times 0,05 \mathrm{~L}}{0,9999 \mathrm{~g} \times 10^{-3} \mathrm{~g} / \mathrm{Kg}}=12,3012 \mathrm{mg} / \mathrm{Kg}$

Konsentrasi logam $\mathrm{Cu}(\mathrm{mg} / \mathrm{Kg})$ Ulangan 2

$=\frac{0,182\left(\frac{\mathrm{mg}}{\mathrm{L}}\right) \times 0,05 \mathrm{~L}}{1,0009 \mathrm{~g} \times 10^{-3} \mathrm{~g} / \mathrm{Kg}}=9,0918 \mathrm{mg} / \mathrm{Kg}$

Konsentrasi $\mathrm{Cu}(\mathrm{mg} / \mathrm{Kg})$

$=\frac{\text { Konsentrasi } \mathrm{Cu} \text { (Ulangan1) }+ \text { Konsentrasi } \mathrm{Cu} \text { (Ulangan2) }}{2}$

$=\frac{(12,3012+9,0918) \mathrm{mg} / \mathrm{Kg}^{2}}{2}=10,6965 \mathrm{mg} / \mathrm{Kg}$

Kandungan logam berat pada akar lebihtinggi dibandingkan dengan sludge dankandungan logam di sludge lebih besar dibandingkan di air. Hal ini sesuai dengan pernyataan Setiawan (2013) dalam Fadhilla dkk., (2018) yang menyatakan besarnyakonsentrasi logam di jaringan akar diduga karena jaringan akar mempunyai interaksi langsung dan terus-menerus dengan sludge dan air yang telah terkontaminasi oleh logamyang mengendap, sehingga logam akan terakumulasi di akar. Logam berat yang berada di akar akan terakumulasi sampaitanaman tersebut tidak mampu menahan toksisitas logam berat tersebut yang akhirnya akan dikeluarkan oleh proses ekskresi. Sedangkan logam berat di sludge lebih besar di air karena adanyapengendapan pada sludge pada saat kandungan logam berat tinggi di air, danlogam berat yang mudah berikatan dengan bahan organik sehingga mengendap dan berikatan dengan parikel sludge.

Tabel 2. Perbandingan Kadar Logam Berat $\mathrm{Cu}, \mathrm{Pb}$, dan $\mathrm{Zn}$ dalam air dengan Baku Mutu Lingkungan Keputusan Menteri Lingkungan Hidup No. 51 Tahun 2004 Lampiran III

\begin{tabular}{cccccccc}
\hline $\begin{array}{c}\text { Jenis Logam } \\
\text { Berat }\end{array}$ & \multirow{2}{*}{ Baku Mutu } & Titik 1 & Titik 2 & Titik 3 & Titik 4 & Titik 5 & Rerata \\
\hline Tembaga (Cu) & $0,008 \mathrm{mg} / \mathrm{L}$ & 0,027 & 0,020 & 0,015 & 0,011 & 0,030 & $\mathbf{0 , 0 2 1}$ \\
\hline Timbal $(\mathbf{P b})$ & $0,008 \mathrm{mg} / \mathrm{L}$ & 0,002 & 0,002 & 0,002 & 0,003 & 0,008 & $\mathbf{0 , 0 0 3}$ \\
\hline Seng (Zn) & $0,005 \mathrm{mg} / \mathrm{L}$ & 0,3680 & 0,3930 & 0,3720 & 0,3580 & 0,4110 & $\mathbf{0 , 3 8 0 4}$ \\
\hline
\end{tabular}

Sumber : Data primer, 2020

Hasil analisis kandungan logam berat $\mathrm{Cu}$ (tembaga), $\mathrm{Pb}$ (timbal), dan $\mathrm{Zn}$ (seng) diTWAM Angke Kapuk di perairan rata-rata adalah 0,021 mg/L untuk logam Cu, 0,003 mg/L untuk logam 
Jurnal SEOI - Fakultas Teknik Universitas Sahid Jakarta

Vol 3 edisi 2 tahun 2021

$\mathrm{Pb}$, dan 0,3804 mg/Luntuk logam Zn. Sesuai Keputusan Menteri Lingkungan Hidup No. 51 Tahun 2004 Lampiran III menyatakan konsentrasi logam $\mathrm{Cu}$ dan $\mathrm{Pb}$ didalam perairan 0,008 mg/L sedangkan untuk Zn 0,005 mg/L. Logamberat $\mathrm{Cu}$ dan $\mathrm{Zn}$ telah melewati baku mutu yang telah ditetapkan. Menurut Hutagalung (1991) dalam Supriyantini, E (2017), logamberat yang masuk ke perairan mengalami beberapa proses yaitu; (1) proses fisika, seperti pengenceran, sedimentasi, transportasi oleh arus dan difusi molekuler, (2) proses kimia, seperti reaksi kimiadengan zat lain ataupun terurai olehoksidasi oksigen, dan (3) proses biologi. Kelebihan kadar logam $\mathrm{Cu}$ dan $\mathrm{Zn}$ berasal dari aktifitas manusia dan industri yang ada disekitar muara angke dan yang aliran airnyabermuara ke muara angke. Aktifitas manusiasalah satu contohnya adalah melalui polusi udara yang mengandung logam berat sepertiCu dan $\mathrm{Zn}$ akan terbawa turun bersama hujan yang akan masuk ke dalam perairan. Logam berat $\mathrm{Cu}$ dan $\mathrm{Zn}$ yang larut keperairan akan terbawa sampai ke muara angke dan terakumulasi sehingga konsentrasinya relatif besar karena mudah terdistribusi. Kadar $\mathrm{Cu}$ dan $\mathrm{Zn}$ semakin lama akan semakin meningkat seiring dengan bertambahnya polutan yang masuk ke dalam perairan apabila tidak dilakukan tindakkan penanggulangan.

\begin{tabular}{|c|c|c|c|c|c|c|c|}
\hline Jenis Logam & Baku & & & Konsentr & asi logan & $(m g / L)$ & \\
\hline Berat & Mutu & Titik 1 & Titik 2 & Titik 3 & Titik 4 & Titik 5 & Rerata \\
\hline Tembaga (Cu) & $65 \mathrm{mg} / \mathrm{Kg}$ & 0,5499 & 0,6198 & 0,4599 & 0,3199 & 0,3800 & 0,4659 \\
\hline Timbal (Pb) & $50 \mathrm{mg} / \mathrm{Kg}$ & 0,2400 & 0,3199 & 0,2100 & 0,1600 & 0,1600 & 0,2180 \\
\hline Seng (Zn) & $410 \mathrm{mg} / \mathrm{Kg}$ & 2,7398 & 2,7800 & 2,0797 & 2,1196 & 2,0398 & 2,3518 \\
\hline
\end{tabular}

Sumber : Data primer, 2020

Hasil analisis kandungan logam berat $\mathrm{Cu}$ (tembaga), $\mathrm{Pb}$ (timbal), dan $\mathrm{Zn}$ (seng) pada sludge rata rata adalah $0,4659 \mathrm{mg} / \mathrm{Kg}$ untuk logam $\mathrm{Cu}, 0,2180 \mathrm{mg} / \mathrm{Kg}$ untuk logamPb, dan 2,3518 mg/Kg untuk logam Zn. Titik 2 konsentrasi logam berat di sludgenya tertinggi dan terendah pada titik 4 dan 5. Titik 2 konsentrasi logam beratnya tertinggidikarenakan sludge pada titik 2 berbentuk lempung berlumpur. Tipe sludge juga mempengaruhi konsentrasi logam berat. Menurut Bernhard (1981) dalam Supriyantini, E (2017), kandungan logamberat umumnya lebih tinggi ditemukandalam sludge yang berbentuk lempung, lumpur, pasir berlumpur, dan akan berkurang pada pasir. Semakin kecil ukuran partikel semakin besar kandungan logam beratnya. Hal ini disebabkan karena partikel sludge yang halus memiliki luas permukaan yang besar dengan kerapatan ion lebih stabiluntuk mengikat logam daripada partikel sludge yang besar, sehingga sludge dengan partikel lebih kecil memiliki kemampuan menyerap relatif lebih tinggi (Madusari dkk.,(2016) dalam Wulandari dkk., (2018)).

Hasil analisis kandungan logam berat pada sludge dibandingkan dengan Australian and New Zealand Environment and Conservation Council (ANZECC,2000) yang menyatakan baku mutu konsentrasi logam $\mathrm{Cu}, \mathrm{Pb}$, dan $\mathrm{Zn}$, pada sludge masing-masing adalah $65 \mathrm{mg} / \mathrm{Kg}, 50 \mathrm{mg} / \mathrm{Kg}$, dan $410 \mathrm{mg} / \mathrm{Kg}$. Konsentrasi logamberat $\mathrm{Cu}, \mathrm{Pb}$, dan $\mathrm{Zn}$ telah memasuki baku mutu yang ditetapkan. Kandungan logamberat di sludge ini cukup rendah, hal inidapat disebabkan karena mangrove yang tumbuh pada fase pertumbuhan pohon menyerap dan mengakumulasi logam berat yang cukup besar dari sludge. Jundana, dkk.(2016) menyatakan bahwa kandunganlogam berat pada fase pohon pada organ akarlebih besar menyerap logam berat daripada tingkat pancang dan semai.

Kandungan logam berat $\mathrm{Cu}, \mathrm{Pb}$, danZn di akar rata-rata adalah 8,7950 mg/Kguntuk $\operatorname{logam~} \mathrm{Cu}, 0,9592 \mathrm{mg} / \mathrm{Kg}$ untuk logamPb, dan $14,7934 \mathrm{mg} / \mathrm{Kg}$ untuk logam Zn. Kandungan logam $\mathrm{Zn}$ diakar hasilnya tertinggi dan yang terendah adalah $\mathrm{Pb}$. Kandungan logam berat yang masuk kedalam akar mangrove ini sebagiandigunakan untuk metabolisme mangrovedan 
Jurnal SEOI - Fakultas Teknik Universitas Sahid Jakarta

Vol 3 edisi 2 tahun 2021

memang A. marina ini dapat menyerap racun. Hal ini sesuai dengan penelitian BalaiPenelitian dan Konsultasi Industri Surabayadiketahui bahwa mangrove A.marina memiliki pengaruh dalam penanggulangan materi toksik lain di antaranya denganmelemahkan efek racun melalui pengenceran (dilusi), yaitu dengan menyimpan banyak air di dalam jaringanbiasanya terjadi pada daun dan diikutidengan terjadinya penebalan daun (sukulensi). Ekskresi juga merupakan upayayang mungkin terjadi, yaitu dengan menyimpan materi toksik logam berat didalam jaringan yang sudah tua seperti daun yang sudah tua dan kulit batang yang mudahmengelupas, sehingga dapat mengurangi konsentrasi logam berat di dalam tubuhnya. Metabolisme atau transformasi secara biologis (biotransformasi) logam berat dapatmengurangi toksisitas logam berat. Logam berat yang masuk ke dalam tubuh akan mengalami pengikatan dan penurunan daya racun, karena diolah menjadi bentuk-bentukpersenyawaan yang lebih sederhana. Proses ini dibantu dengan aktivitas enzim yang mengatur dan mempercepat jalannya prosestersebut (Halidah,2014).

3.2. Bio-concentration factor (BCF) Logam Berat Cu (Tembaga), Pb (Timbal), dan Zn (Seng)

Bio-concentration factor (BCF) adalah konsentrasi suatu senyawa didalam suatu organisme percobaan dibagi dengan konsentrasi senyawa tersebut dalam mediumsludge satuannya $\mathrm{mg} / \mathrm{L}$ (Awaliyah dkk., 2018). Nilai BCF A. marina didapatkan dengan cara membagi konsentrasi logam berat $\mathrm{Cu}, \mathrm{Pb}$, dan $\mathrm{Zn}$ yang ada di akar dengankonsentrasi logam berat $\mathrm{Cu}, \mathrm{Pb}$, dan $\mathrm{Zn}$ yangterdapat di sludge. Nilai BCF dihitung untukmengetahui kemampuan A. marina dalam mengakumulasi logam berat $\mathrm{Cu}, \mathrm{Pb}$, dan $\mathrm{Zn}$.Nilai BCF dapat kita lihat pada Tabel 4

Tabel 4. Bio-concentration factor (BCF) Logam Berat $\mathrm{Cu}$ (Tembaga), Pb (Timbal), dan Zn (Seng)

\begin{tabular}{|l|c|c|c|c|c|c|c|c|c|}
\hline \multirow{2}{*}{ Lokasi } & \multicolumn{3}{|c|}{ Logam berat Cu} & \multicolumn{4}{c|}{ Logam Berat $P b$} & \multicolumn{3}{c|}{ Logam Berat Zn } \\
\cline { 2 - 10 } & Sludge & Akar & $B C F$ & Sludge & Akar & $B C F$ & Sludge & Akar & $B C F$ \\
\hline Titik 1 & 0,5499 & 10,6965 & 19,45 & 0,2400 & 0,9991 & 4,16 & 2,7398 & 16,8017 & 6,13 \\
\hline Titik 2 & 0,6198 & 11,1150 & 17,93 & 0,3199 & 1,8482 & 5,78 & 2,7800 & 16,9830 & 6,11 \\
\hline Titik 3 & 0,4599 & 7,2471 & 15,76 & 0,2100 & 0,8996 & 4,28 & 2,0797 & 13,4433 & 6,46 \\
\hline Titik 4 & 0,3199 & 6,7698 & 21,16 & 0,1600 & 0,3498 & 2,19 & 2,1196 & 13,5419 & 6,39 \\
\hline Titik 5 & 0,3800 & 8,1484 & 21,45 & 0,1600 & 0,6993 & 4,37 & 2,0398 & 13,1974 & 6,47 \\
\hline BCF & & & $\mathbf{1 9 , 1 5}$ & & & $\mathbf{4 , 1 6}$ & & & $\mathbf{6 , 3 1}$ \\
\hline
\end{tabular}

Sumber : Data primer, 2020

Berdasarkan hasil perhitungan nilai bio-concentration factor $(\mathrm{BCF}) \log a \mathrm{~m} \mathrm{Cu}, \mathrm{Pb}$, dan $\mathrm{Zn}$ masing-masing adalah 19,15;4,16; dan 6,31. Nilai BCF tertinggi adalah logam $\mathrm{Cu}$ dan nilai BCF terendah adalah logam $\mathrm{Pb}$. Logam $\mathrm{Cu} \mathrm{BCF}$ nya tertinggikarena nilai logam di akar cukup besar tetapidi sludgenya kecil, artinya logam sudah berpindah ke tanaman mangrove $A$. marina dengan waktu yang cukup lama. Sedangkanlogam $\mathrm{Pb}$ kecil karena akar mangrove dalammenyerap logam $\mathrm{Pb}$ itu kurang.

Hasil penelitian ini menunjukkan nilaiBCF logam berat $\mathrm{Cu}, \mathrm{Pb}$ dan $\mathrm{Zn}$ lebih dari satu, maka mangrove A. marina dapatmengakumulasi logam berat. Janssen dkk. (1997) dalam Fadhilla dkk. (2018) menyatakan bahwa apabila nilai BCF > 1 dari konsentrasi yang ada di kolom air berarti organisme tersebut memiliki kemampuan mengakumulasi logam dalam tubuhnya (hiperakumulator). Sehingga dapatdijadikan indikator bahwa tanaman mangrove A. marina di Taman Wisata AlamMangrove Angke Kapuk Jakarta dapat menyerap logam-logam berat di perairan dansludge.

Nilai BCF ini perlu dihitung dan diketahui karena nilai BCF ini dapat digunakan sebagai salah satu penentu untukfitoremediasi. Fitoremediasi didefinisikan sebagai pencucian polutan yang dimediasi oleh tumbuhan termasuk pohon, rumput- rumputan, dan tumbuhan air (Smith dkk., 1997 dalam Silvia dkk., 2019). Pencucian bisa berarti penghancuran, inaktivasi polutanke 
bentuk yang tidak berbahaya (Chaney et al.1995 dalam Silvia dkk., 2019). Fitoremediasi merupakan satu-satunya metode pengolahan limbah yang menggunakan tanaman sebagai indikator, mudah untuk diaplikasikan, tidak memakan biaya banyak, dan tanaman yang digunakanjuga banyak terdapat di alam (Melethia dkk,1996 dalam Silvia dkk., 2019). Apabila nilai $\mathrm{BCF}>1$, maka mangrove dapat menyerap logam-logam tertentu sehingga mengurangi pencemaran logam berat di alam secara biologi dan lebih aman bagilingkungan. Tindakan pemulihan perlu dilakukan agar tanah yang tercemar dapat digunakan kembali dengan aman. Banyakteknologi yang digunakan untuk remediasi tanah yang tercemar logam berat. Salah satu cara adalah dengan menggunakan tanaman, yaitu dengan cara menanam tanaman yang mampu menyerap logam berat dari dalam tanah. Contoh tanaman yang mampu menyerap logam berat selain mangrove adalah Casuarina junghuniana, Pinus merkusii, Melia azedarach, dan Gmelina arborea. Tanaman tersebut telah diteliti di media tailing PT Antam UBPE Pongkor dandapat digunakan pada kegiatan fitoremediasidi lapangan karena mampu tumbuh padamedia tailing dan menyerap logam cukup tinggi dalam jaringan tanaman. (Zakiyah, 2015).

\section{KESIMPULAN}

Berdasarkan penelitian yang telah dilakukan di Taman Wisata Alam Mangrove Angke Kapuk dapat disimpulkan bahwa:

1. Kandungan logam berat $\mathrm{Cu}$ (tembaga), $\mathrm{Pb}$ (timbal), dan $\mathrm{Zn}$ (seng) di Taman Wisata Alam Mangrove Angke Kapuk di perairanrata-rata adalah 0,021 mg/L, 0,003 mg/L, dan 0,3804 mg/L. Sedangkan kandungan logam berat $\mathrm{Cu}$ (tembaga), $\mathrm{Pb}$ (timbal), dan $\mathrm{Zn}$ (seng) pada sludge ratarata adalah0,4659 mg/Kg, 0,2180 mg/Kg, dan 2,3518 mg/Kg . Kandungan logam berat $\mathrm{Cu}, \mathrm{Pb}$, dan Zn di akar rata-rata adalah $8,7950 \mathrm{mg} / \mathrm{Kg}, 0,9592 \mathrm{mg} / \mathrm{Kg}$, dan 14,7934 mg/Kg. Logam berat $\mathrm{Cu}$ dan $\mathrm{Zn}$ telah melewati baku mutu yang telah ditetapkan sedangkan logam $\mathrm{Pb}$ memenuhi baku mutu yang ditetapkan. Taman Wisata Alam Mangrove AngkeKapuk secara keseluruhan untuk sludge belum tercemar logam $\mathrm{Cu}, \mathrm{Pb}$, dan $\mathrm{Zn}$ karena masih di bawah baku mutu yang ditentukan.

2. Kemampuan $A$. marina dalammengakumulasi logam $\mathrm{Cu}, \mathrm{Pb}$, dan Znmasing- masing adalah 19,15; 4,16; dan 6,31. Nilai BCF melebihi satu menyatakan bahwa mangrove A. marina di Taman Wisata Alam Mangrove AngkeKapuk Jakarta dapat mengakumulasikan logam berat. Nilai BCF ini dapat digunakan untuk menentukan jenis fitoremediasi dari tanaman mangrove. Mengetahui jenis fitoremediasi ini dilakukan perhitungan nilai Translokasi dengan membandingkan nilai BCF logamberat pada bagian batang dan daun mangrove A. marina. Selain itu penetapan nilai BCF ini dapat dilakukan untuk berbagai jenis tanaman untuk mengetahui kemampuan bioakumulasi dari tanaman sehingga dapat digunakan sebagai pengolahan limbah logam berat. Penelitian bioakumulasi logamberat yang telah dilakukan pada akar mangrove A. marina terbukti mampu mengakumulasi logam berat di perairan. Kemampuan A. marina dalam mengakumulasi logam berat ini maka,perlu dilakukan penelitian lanjutan.Penelitian selanjutnya dapat juga dilakukan perhitungan akumulasi logam berat pada bagian batang dan daun darimangrove, untuk menentukan nilai translokasi sehingga dapat mengetahui jenis fitoremediasi tanaman. Selain itu dapat juga dilakukan penelitian dengan jenis spesies mangrove yang berbeda sehingga dapat dilakukan perbandingan kemampuan penyerapan logam berat dari dua jenis mangrove yang berbeda. Perbandingan jenis mangrove tersebut dapat memberi informasi jenis mangrove yang lebih maksimal dalam menyeraplogamlogam berat secara spesifik di alam. Selain itu, untuk mengurangi pencemaran logam berat dan memberikan effisiensi untuk pemilihan jenis mangrove yang akanditanam di daerah-daerah 
Jurnal SEOI - Fakultas Teknik Universitas Sahid Jakarta

Vol 3 edisi 2 tahun 2021

pencemaran logam berat spesifik dengan kadar yangtinggi.

\section{DAFTAR PUSTAKA}

American Public Health Association, American Water Works Assosiation dan Water Pollution ControlFederation. 2005. Standard Methods for the Examination of Water and Wastewater, AWWA, WPCF. 21st Eds. Hal 3-10.

Australian and New Zealand Environment and Conservatien Council(ANZECC), (2000), ANZECC interim sediment quality guidlines. Report forthe environmental research institute ofthe supervising scientist.Sydney,Australia.

Awaliyah, H. F., Yona, D., dan Pratiwi, D.C. (2018). Akumulasi logam berat Pb dan Cu pada akar dan daun mangrove Avicennia marina di SungaiLamong, Jawa Timur. Jurnal IlmuIlmu Perairan, Pesisir dan Perikanan. p-ISSN: 2089-7790, e-ISSN: 2502- 6194.

Chodriyah, U., dan Pralampita, W., A. (2019).Penanganan Sedimentasi Di Daerah Muara Sungai Bagi KepentinganPengoperasian Pelabuhan Perikanan Peneliti pada Balai Riset Perikanan Laut. Jurnal Bawal. Volume 2(5):249-252.

Fadhilah, A., Hamdani, H., Sunarto, dan Sahidin, A. (2018). Daya Serap Akar Mangrove Avicennia marina TerhadapLogam Berat Timbal $(\mathrm{Pb})$ di Perairan Taman Wisata Alam Angke Kapuk Jakarta. Universitas Padjadjaran. JawaBarat. Volume IX(2):80-86.

Halidah. (2014). Avicennia marina (Forssk.) Vierth Jenis Mangrove yang Kaya Manfaat. Jurnal Balai PenelitianKehutanan Makassar. Volume11(1):37-44.

Hamzah, F., dan Setiawan, A. (2010). Akumulasi Logam Berat Pb, Cu, dan Zn di Hutan Mangrove Muara Angke,Jakarta Utara. Jurnal Ilmu dan Teknologi Kelautan Tropis, Volume2(2):4152.

Jundana, A. F., Hastuti, E., dan Budihastuti, R. (2016). Daya Akumulasi Logam Berat Tembaga (Cu) Pada Akar Dan Daun Avicennia Marina (Forsk.) Berdasarkan Fase Pertumbuhan Yang Berbeda Di Pantai Mangkang Semarang. Jurnal Biologi, Volume 5(3):36-46.

Keputusan Menteri Lingkungan Hidup No.51/Men KLH/I/2004 TentangBaku Mutu Air Laut.

Silvia, M. B., Mariwy, A., dan Manuhuttu, J.(2019). Fitoremediasi Tanah Tercemar Logam Berat Merkuri (Hg) Menggunakan Tumbuhan Kersen (Muntingia Calabua L) Dengan Sistem Reaktor. Molluca Journal of Chemistry Education. Volume9(2):78-89. ISSN: 2087-9024.

Sucita, F., dan Aviantara, D., B. (2019). StudiLingkungan Tempat PemrosesanAkhir Sampah Galuga Kecamatan Cibungbulang Kabupaten Bogor Provinsi Jawa Barat. Jurnal Studi Lingkungan Tempat. Volume 12(2):155-174. p-ISSN: 2085.38616, e-ISSN: 2580-0442.

Supriyantini, E., Nuraini, R. A. T. , danDewi, C. P. (2017). Daya Serap Mangrove Rhizophora sp. Terhadap Logam Berat Timbal $(\mathrm{Pb})$ Di Perairan Mangrove Park, Pekalongan. Jurnal Kelautan Tropis. Volume 20(1):16-24.

U.S. EPA, Toxicity Characteristic Leaching Procedure, Washington: U.S. Environmental Protection Agency (1992).

Undang-undang Republik Indonesia. 2009. Undang-undang Republik Indonesia Nomor 32 Tahun 2009 tentangPerlindungan dan PengelolaanLingkungan Hidup. Jakarta:Sekretariat Negara.

Utami, R., Rismawati, W., dan Sapanli, K. (2018). Pemanfaatan Mangrove Untuk Mengurangi Logam Berat Di Perairan.Jurnal Prosiding Seminar Nasional Hari Air Dunia 2018.

Wulandari,T., Budihastusi, R., dan Hastuti, E. D. (2018). Kemampuan Akumulasi Timbal (Pb) 
Jurnal SEOI - Fakultas Teknik Universitas Sahid Jakarta

Vol 3 edisi 2 tahun 2021

Pada Akar Mangrove Jenis Avicennia Marina (Forsk.) Dan Rhizophora Mucronata (Lamk.) Di Lahan Tambak MangunharjoSemarang. Jurnal Biologi, Volume 7(1):89-96.

Zakiyah, Roisatuz. (2015). Uji Pertumbuhan Dan Kemampuan Empat Jenis Tanaman dalam Menyerap Logam Berat pada Media Tailing PT Antam UBPE Pongkor. Bogor. Institut Pertanian Bogor. 